\title{
THE EFFECT OF NATIONAL CULTURE ON THE CHOICE OF ENTRY MODE
}

\author{
Bruce Kogut* \\ Stockholm School of Economics \\ Harbir Singh** \\ University of Pennsylvania
}

\begin{abstract}
Characteristics of national cultures have frequently been claimed to influence the selection of entry modes. This article investigates this claim by developing a theoretical argument for why culture should influence the choice of entry. Two hypotheses are derived which relate culture to entry mode choice, one focussing on the cultural distance between countries, the other on attitudes towards uncertainty avoidance. Using a multinomial logit model and controlling for other effects, the hypotheses are tested by analyzing data on 228 entries into the United States market by acquisition, wholly owned greenfield, and joint venture. Empirical support for the effect of national culture on entry choice is found.
\end{abstract}

Foreign direct investment into the United States has grown dramatically since the early 1970s. Accompanying this increase has been a growth of academic work studying the phenomenon. ${ }^{1}$ Whereas impressive information concerning foreign direct investment in the United States in general is available, there has been surprisingly few statistical investigations concerning the choice of entry modes.

The objective of this article is two-fold. First, original data regarding the choice of entry mode by foreign firms is described in terms of country and industry patterns. Second, the factors that influence the choice between joint ventures, wholly owned greenfield (i.e., start-up) investments, and acquisitions are analyzed statistically. In particular, the statistical investigation seeks to

*Bruce Kogut is a Visiting Professor at the Institute of International Business at the Stockholm School of Economics and is on leave from the Wharton School.

**Harbir Singh is an Associate Professor of Management at the Wharton School of Business. His prior research is on corporate acquisitions and on top management incentives, and has been published in the Academy of Management Journal and the Strategic Management Journal.

Of the many helpful contributions, the authors would like to acknowledge Erin Anderson, Ned Bowman, Mark Casson, Richard Caves, Wujin Chu, Hubert Gatignon, Jean Francois Hennart, Jake Jacoby, Tom Pugel, Steve Young, and the anonymous referees. The authors thank Dileep Hurry, Ommer Khaw, Eirene Chen, and Criag Stevens for their research assistance. Funding for the project was provided by the Reginald H. Jones Center of the Wharton School under a grant from AT\&T.

Received: April 1986; Revised: September 1986, March 1987 \& February 1988; Accepted: February 1988. 
explain a striking difference among countries regarding their propensities to enter by acquisition versus other modes. These differences in country propensities towards acquisitions are examined in a framework which relates aspects of a nation's culture to preferences regarding the governance of foreign operations. ${ }^{2}$

This article represents the first statistical test of the relationship between culture and entry choice as an explanation of country patterns of entry modes while controlling for firm- and industry-level variables. Because our measure of culture is derived from the indices of Hofstede [1980], the results validate the usefulness of his constructs, though this was not our primary intention. Moreover, the findings suggest that transaction cost explanations for mode of entry choice must be qualified by factors stemming from the institutional and cultural context. ${ }^{3}$

\section{A PREFATORY NOTE ON TERMINOLOGY}

It is important at the outset to define terminology. This article looks at three kinds of entry modes: acquisitions, joint ventures, and greenfield investments. Acquisitions refer to the purchase of stock in an already existing company in an amount sufficient to confer control. All of the acquisitions in our study consist of a controlling equity share with the remaining shares dispersed across many investors. A joint venture is the pooling of assets in a common and separate organization by two or more firms who share joint ownership and control over the use and fruits of these assets. ${ }^{4}$ A greenfield investment is a start-up investment in new facilities. Such an investment can be wholly owned or a joint venture. For purposes of simplifying the exposition, we classify all start-up investments which are wholly owned under greenfield and those which involve shared ownership under joint venture.

Many studies, as discussed later, have treated greenfield and acquisition as representing alternative entry modes, with joint ventures being only a question of the degree of ownership. This approach implies that entry and ownership involve two sequential decisions, the first deciding whether to invest in new facilities or to acquire existing ones, the second one on how ownership should be shared. Whereas such an approach is clearly defensible on both theoretical and empirical grounds, we treat joint ventures as a choice made simultaneously with other alternative modes of entry.

Our reasoning can be tersely summarized as follows. Conceptually, it could well be argued that joint ventures are not merely a matter of equity control, but represent a set of governance characteristics appropriate for certain strategic or transaction cost motivations or for the transfer of tacit organizational knowledge [Kogut 1987]. Joint ventures are vehicles by which to share complementary but distinct knowledge which could not otherwise be shared or to coordinate a limited set of activities to influence the competitive positioning of the firm. Empirically, the evidence on whether managers consider joint ventures sequential to, or simultaneous with, other entry choices is slim. It is of interest, therefore, that Gatignon and Anderson [1987], whose results are described in more detail later, find that their statistical model of entry choice discriminates well between wholly owned and shared control choice of entries, but not between wholly 
owned and the degree of shared control. This finding suggests that managers perceive the choice as between wholly owned and joint venture (and possibly other entry modes), with degree of ownership being explained by other factors, such as perhaps the bargaining power of the parties. ${ }^{5}$ Consequently, due both to the above conceptual and empirical reasons, we frame the joint venture choice as made simultaneously in consideration with other entry alternatives.

\section{THEORETICAL FRAMEWORK}

The theory underlying our approach reflects in some ways a return to an older line of thought in the work on foreign direct investment. Since the publication of Stephen Hymer's thesis in 1960, the economic theory of foreign direct investment has been driven not by country-level variables, such as differences in interest rates, but by industry- and firm-level variables [Hymer 1960]. Industry-level variables reflect barriers to entry and patterns of oligopolistic behavior. Firm-level variables are related to the concept of transaction costs, whereby the transfer of specialized assets between firms is impeded by market failures, thus necessitating the expansion of the firm (in some cases across borders) in order to internalize the transfer. To the extent that the same variables influence whether to enter by foreign direct investment, licensing, or exporting, the choice of the mode of entry is jointly and simultaneously determined. ${ }^{6}$

Because our emphasis in this article is upon country patterns in the entry mode propensities, we do not seek to develop a full theory of entry choice. Rather, we concentrate on only those factors likely to affect national patterns. Observations on differences among countries in their propensities to joint venture, acquire, or invest in greenfield sites have been made by Robinson [1961], Brooke and Remmers [1972], Franko [1976], and Stopford and Haberich [1978] in relation to the lower frequency of overseas joint venture activity by American firms compared to that by European firms. In his study on foreign acquisitions, Wilson [1980] found that there were significantly different patterns of acquisition among American, British and Japanese corporations.

A number of previous studies lend theoretical and empirical support to the relationship between a firm's country of origin and the mode of entry. Two studies, in particular, isolate the influence of culture on entry mode patterns. The investigations by researchers at the University of Uppsala related foreign direct investment patterns to the "psychic distance" between countries. ${ }^{7}$ By psychic distance, it is meant the degree to which a firm is uncertain of the characteristics of a foreign market. Psychic distance, they reasoned, would be influenced by differences in the culture and language of the home and target countries. Similarly, Puxty [1979] speculated on the relationship between cultural differences and ownership policies regarding overseas subsidiaries. Neither of these studies, however, laid out systematically how cultural differences influence entry choices, or provided large-sample statistical evidence.

We seek to explain differences in country propensities in the choice of entry modes from the point of departure that differences in cultures among countries influence the perception of managers regarding the costs and uncertainty of 
alternative modes of entry into foreign markets. Assuming revenues constant across alternatives, managers will choose the entry mode which minimizes the perceived costs attached to the mode of entry and subsequent management of the subsidiary. Because differences in national cultures have been shown to result in different organizational and administrative practices and employee expectations, it can be expected that the more culturally distant are two countries, the more distant are their organizational characteristics on average [Bendix 1956; Lincoln, Hanada and Olson 1981]. If cultural factors influence differentially the perceived or real costs and uncertainty of the mode of entry, there should exist country patterns in the propensity of firms to engage in one type of entry mode as opposed to others.

Due to the difficulty of integrating an already existing foreign management, cultural differences are likely to be especially important in the case of an acquisition. Indeed, empirical studies on mostly domestic acquisitions have shown that post-acquisition costs are substantial and are influenced by what Jemison and Sitkin [1986] call the organizational fit of the two firms. They define organizational fit as "the match between administrative practices, cultural practices, and personal characteristics of the target and parent firms" [Jemison and Sitkin 1986, p. 147]. Sales and Mirvis [1984] document in detail the administrative conflicts following an acquisition when both firms differ strongly in their corporate cultures.

In contrast to the integration costs of an acquisition, a joint venture serves frequently the purpose of assigning management tasks to local partners who are better able to manage the local labor force and relationships with suppliers, buyers, and governments [Franko 1971; Stopford and Wells 1972]. Thus, a joint venture resolves the foreign partner's problems ensuing from cultural factors, though at the cost of sharing control and ownership. Unquestionably, a joint venture is affected by the cultural distance between the partners. But such conflict should not obscure the original motivation to choose a joint venture because the initial alternative of integrating an acquisition appeared more disruptive than delegating management tasks to a local partner. Of course, a joint venture may be troubled not only by the cultural distance of the partners, but also due to concerns over sharing proprietary assets. A wholly owned greenfield investment avoids both the costs of integration and conflict over sharing proprietary assets by imposing the management style of the investing firm on the start-up while preserving full ownership. ${ }^{8}$

For this reason, we expect that the use of acquisitions by foreign firms entering the United States should be dissuaded, the more distant the culture of the country of origin. ${ }^{9}$ The following analysis tests the relationship of cultural factors to country patterns in entry mode choice under two different hypotheses:

1. The greater the cultural distance between the country of the investing firm and the country of entry, the more likely a firm will choose a joint venture or wholly owned greenfield over an acquisition.

2. The greater the culture of the investing firm is characterized by uncertainty avoidance regarding organizational practices, the more 
likely that firm will choose a joint venture or wholly owned greenfield over an acquisition.

Hypothesis 1 is derived from the premise that firms from culturally distant countries will attach greater costs to the management of acquisitions relative to joint ventures or to wholly owned greenfield investments than firms from culturally similar countries. ${ }^{10}$ These costs may be perceptual only or accurate appraisals of the increased difficulties of managing a foreign workforce in a culturally distant country. Hypothesis 2 is derived from the premise that acquisitions confront firms with greater uncertainty over the management of foreign operations. ${ }^{11}$ Therefore, firms from countries characterized by relatively high uncertainty avoidance in their organizational practices will tend towards joint ventures or greenfield investments.

\section{LITERATURE REVIEW}

There have been several previous studies which have found that entry choice is influenced by the firm's uncertainty over the characteristics of the targetted countries. In this section, the central findings are reviewed. These studies differ in terms of which entry modes are being compared and are, as a result, complex to compare. The implications for the choice of entry mode are sorted out more clearly in a subsequent section when discussing the relationship of the explanatory variables.

A common theme in a number of studies has been the identification of perceived uncertainty as a function of a firm's experience in a country. In developing their theory of internationalization based on the Uppsala school's work on psychic distance, Johanson and Vahlne [1977] attributed the evolutionary process by which a firm advances from exporting to joint venturing and wholly owned subsidiaries to the reduction in perceived risk regarding the foreign market as a firm gains in experience. They did not, however, explore the implications for country patterns in entry mode behavior from psychic distances between countries, nor stipulate clearly how the experience of the firm mitigates perceived uncertainty arising from differences in cultures.

The influence of firm experience on entry choice has played a prominent role in several of the studies employing the Harvard Multinational Enterprise Data Base. In their pioneering study on the ownership structure of American multinational firms, Stopford and Wells [1972] found joint ventures, relative to wholly owned activities, were less likely to be chosen, the more central the product to the core business of the firm and more experience the firm had in the relevant country. Similarly, they found that marketing and advertising intensity, as well as research and development intensity, discouraged the use of joint ventures.

Dubin [1975] turned to an investigation of the determinants of foreign acquisitions by American firms over the period of 1948 to 1967. Using bivariate crosstabulations without statistical testing, he found that the tendency to acquire fell with the size of the firm, its foreign experience, and if the target country was an LDC. His findings, thus, suggest an increasing use of acquisitions the 
lower the cultural and physical barriers between the home and host countries and the more experience the firm has in the foreign market.

Davidson [1980] analyzed a version of the Multinational Enterprise Data Base which was updated from 1967 to 1975 and traced the establishment of foreign subsidiaries from their inception. Through the identification of statistically significant correlations, he found three patterns: 1) that firms will more likely invest where they or their competitors in the same industry have invested before; 2) that countries which have reputedly similar cultures are a preferred target of investment; and 3) that previous firm-level experience in a countryno matter if licensing or joint venture-leads to an increasing likelihood of wholly owned investment for later entries.

The above studies suggest, therefore, that the choice of entry mode is influenced by cultural differences and firm experience. However, because the statistical studies by Dubin [1975] and Davidson [1980] did not test these relationships while controlling for other variables, the explanation for country patterns could be considered to be derived from two spurious relationships. The first is the relationship between the historically greater involvement of particular countries internationally and the influence of firm experience on entry choice. The second is the relationship between differences in industrial composition among countries, differences in the intensity of marketing and research expenditures across industries, and the influence of the desire of firms to control the international extension of marketing- or research-intensive assets.

In the three studies that investigated the determinants of entry mode while statistically controlling for other variables, experience has not, however, been proven to be instrumental in choice of entry mode. Analyzing entry by acquisition versus greenfield for American, British, German and Japanese firms, Wilson [1980] reported that experience did not significantly influence the decision to invest in foreign countries by a greenfield establishment over an acquisition. ${ }^{12}$ The decision to acquire was found, instead, to co-vary positively with diversification and negatively with the proportion of recently established subsidiaries to total establishments and with whether the target country was an LDC.

Caves and Mehra [1986] analyzed 138 decisions of non-American firms to enter the United States by greenfield versus acquisition through a qualitative choice model with industry- and firm-level variables as the independent variables, while controlling for joint ventures. Their data was drawn from a listing of reported announcements for the years of 1974 to 1980 . Their results disconfirmed the hypothesis that previous investments in a country influenced a foreign firm's decision to enter by greenfield over acquisition into the United States. Rather, they found that size of the foreign firm, diversity of its product range, and its degree of multinationality positively and significantly influenced the decision to acquire. In addition, industries producing durable goods were more likely to be characterized by entry through acquisition because, argue Caves and Mehra, the adaptation of durable goods to local conditions requires skills better captured through acquisition than through greenfield investment. 
Joint ventures were found to be negatively related to the choice of acquisitions, thus supporting the premise of this paper that acquisitions and joint ventures are substitute modes of entry. No control was made for country-level variables. In a recent study, Gatignon and Anderson [1987] reanalyzed 1267 entry decisions from the Harvard Multinational Database for the years 1960 to 1974, also using a quantal choice model. As described earlier, their analysis of entry as a three-way decision between wholly owned and various levels of joint venture control was not able to discriminate well between the chosen degree of joint venture ownership. Their binomial test of wholly owned versus joint venture, however, confirmed the Stopford and Wells [1972] bivariate results. Wholly owned subsidiaries (greenfield and acquisition) were favored over partial ownership, the greater the R\&D and advertising intensity of the foreign firm. They also found support that the degree of multinationality had a negative effect on the likelihood to joint venture. ${ }^{13}$ Their dummy variables for regions tended to show strong country patterns. Based on the positive relationships between $R \& D$ and marketing/advertising intensity to wholly owned entries, they conclude that a transaction cost theory of entry choice is supported. ${ }^{14}$

In summary, the literature to date has found that uncertainty over the foreign market influences managers decisions on how to invest overseas, that there are clear but unexplained country patterns in the selection of entry modes, and that both firm- and industry-level variables are related to the choice of entry mode. The previous literature has not, however, clearly extrapolated from the research on cultural traits to implications for country patterns in the relative use of different entry modes, nor has it tested the relationship between cultural factors and entry mode choice while controlling for other factors.

This paper tests explicitly the influence of country cultural characteristics, including attitudes toward uncertainty, upon the choice of the mode of entry into the United States. Though country-level economic variables are currently discounted as explaining why firms invest overseas, cultural differences among countries play a role, this article contends, in explaining how this investment is channeled.

\section{DESCRIPTION OF ENTRY MODE PATTERNS}

Because data comparing entry activities of foreign firms in the United States are not easily available, it is worthwhile to report the patterns found in our sample before turning to statistical tests of the above hypotheses. Whereas aggregated data on foreign acquisitions are routinely available from Department of Commerce publications, similar data for joint ventures are generally lacking. In part, this imbalance can be explained by the significance of acquisitions as a mode of entry for foreign firms into the United States. For the years between 1976 and 1983, acquisitions were responsible for over 50\% of the foreign direct investment in the United States, rising as high as $79 \%$ of the total value in $1981 .{ }^{15}$

On the other hand, data on joint ventures as a mode of entry into the United States is not aggregated and published by the Department of Commerce. While 


\section{TABLE 1}

Distribution of Modes of Entry by Industrial Sector

\begin{tabular}{|c|c|c|c|c|}
\hline & $\begin{array}{c}\text { Joint } \\
\text { Ventures } \\
\end{array}$ & Acquisitions & Greenfield & $\begin{array}{c}\text { Total } \\
\mathrm{N}\end{array}$ \\
\hline Resource & 18 & 35 & 2 & 55 \\
\hline Paper & 3 & 26 & 5 & 34 \\
\hline Chemical & 2 & 15 & 3 & 20 \\
\hline Petroleum & 25 & 35 & 17 & 77 \\
\hline Rubber & 3 & 3 & 2 & 8 \\
\hline Primary Metal & 2 & 20 & 6 & 28 \\
\hline Metal Fabrication & 2 & 8 & 4 & 14 \\
\hline Machinery & 4 & 7 & 0 & 11 \\
\hline \multicolumn{5}{|l|}{ Electrical } \\
\hline Equipment & 24 & 14 & 13 & 51 \\
\hline Transportation & 25 & 21 & 13 & 59 \\
\hline Instrumentation & 10 & 3 & 10 & 23 \\
\hline Other & 3 & 10 & 0 & 13 \\
\hline \multicolumn{5}{|l|}{ Manufacturing } \\
\hline Communication & 1 & 4 & 2 & 7 \\
\hline Wholesale & 8 & 17 & 3 & 28 \\
\hline Financial & 4 & 30 & 0 & 34 \\
\hline \multicolumn{5}{|l|}{ Services } \\
\hline $\begin{array}{l}\text { Other } \\
\text { Services }\end{array}$ & 12 & 25 & 5 & 42 \\
\hline Total & 147 & 274 & 85 & 506 \\
\hline
\end{tabular}

it is thus impossible to have a value estimate of joint ventures, it is possible, based on the sources listed in the appendix, to describe the frequency of the mode of entry across industries and countries. This data is available for acquisitions, greenfield, and joint ventures, as well as other investments not included in this study.

Table 1 provides a breakdown of joint ventures, acquisition, and greenfield by industry for the years 1981 to 1985 . There is a clear difference in industry patterns among the modes of entry. Joint ventures are relatively more frequent in pharmaceuticals/chemicals and electric and nonelectric machinery. Acquisitions occur primarily in natural resources, financial services, and miscellaneous manufacturing industries. Chemical and electrical machinery are especially attractive industries for greenfield investments. At a higher level of aggregation, acquisitions tend to be relatively more common than other modes of entry in nonmanufacturing sectors of the economy.

The country pattern is given in Table 2. Again, there are strong differences among the modes of entry. For Japan, 46 of its 114 entries are joint ventures. ${ }^{16}$ Whereas Japanese acquisitions are not common, Japanese firms have a high proportion of the wholly owned greenfield investments. Scandinavia and, especially France, also lean towards joint ventures. United Kingdom represents the other extreme; 111 of its 141 entries are acquisitions, with the remainder evenly divided between joint ventures and greenfield.

The trends in our sample show clear differences in country propensities regarding the selection of the mode of entry. It is unclear, however, whether these patterns are robust when the relationship is controlled for firm- and industrylevel factors. It could well be that the country pattern is generated by differences 
TABLE 2

Acquisitions, Joint Ventures and Greenfield Entry by Country of
Corporate Headquarters

\begin{tabular}{lcccr}
\hline & $\begin{array}{c}\text { Joint } \\
\text { Ventures }\end{array}$ & Acquisitions & Greenfield & $\begin{array}{r}\text { Total } \\
\text { N }\end{array}$ \\
\hline United & & & & \\
Kingdom & 15 & 111 & 15 & 141 \\
Japan & 46 & 35 & 33 & 114 \\
Scandinavia & 9 & 5 & 4 & 18 \\
Switzerland & 4 & 20 & 3 & 27 \\
Germany & 6 & 10 & 8 & 24 \\
France & 23 & 6 & 4 & 33 \\
Italy & 4 & 3 & 1 & 8 \\
Netherlands & 6 & 24 & 7 & 37 \\
Belgium & 5 & 10 & 0 & 17 \\
Malaysia & 1 & 0 & 2 & 2 \\
S. Africa & 1 & 28 & 3 & 1 \\
Canada & 13 & 20 & 5 & 45 \\
Other & 14 & 274 & 85 & 506 \\
\hline Total & 147 & & &
\end{tabular}

in the sectoral characteristics of foreign direct investment across the countries of origin. The next section gives a formal statistical test to determine the factors influencing the choice of entry.

\section{SELECTION OF VARIABLES}

The hypotheses to be treated posit that the choice of entry is significantly influenced by the cultural characteristics of the home country of the investing firm. Because of the confounding effects of the relationship of firm- and industry-level variables with country identification, it is not possible to test for country effects without controlling for other influences. Consequently, the statistical analysis will investigate the following specification:

$$
\begin{aligned}
\text { Entry Choice }= & f(\text { cultural characteristics; firm variables, industry } \\
\text { variables }) &
\end{aligned}
$$

In previous studies, a number of firm and industry variables have been tested and shown to be significant in explaining the mode of entry choice. These studies indicate several proxies. Because, as discussed below, acquisitions form the baseline case, we discuss the relationship of these proxies to the dependent variable in the context of choosing a joint venture or greenfield relative to acquisition. As our interest is in controlling for specification error, we merely summarize the conventional arguments of the existing literature on the expected relationships between the control variables and the choice variables.

\section{Firm-level Variables}

Diversification [Diversified].

Dubin [1975], Wilson [1980], and Caves and Mehra [1986] have found that firms following diversification strategies are more likely to enter a foreign country by acquisition over greenfield. The presumable explanation for this 
pattern is that diversified firms are competing on superior management and/ or production efficiencies in mature industries, and, therefore, are not concerned with a de novo transfer of a product innovation or brand level. Analogously, diversified firms should be more likely to engage in acquisitions relative to joint ventures.

\section{Country Experience [Experience].}

The effect of previous entry on subsequent entry mode in the same country has not been shown in large-sample multivariate studies to be significant. ${ }^{17}$ Nevertheless, theoretically, we can expect that the propensity to joint venture relative to acquisition should decline as a foreign firm learns more about the local environment. It can also be expected as a firm picks up experience, it is more likely to increase its use of acquisitions relative to joint venturing with local partners.

\section{Multinational Experience [Multinational].}

Contrary to their expectation on the sign of the coefficient, Caves and Mehra [1986] found that multinationality (i.e., the number of countries in which a firm has subsidiaries) is significantly correlated with the choice of acquisition over greenfield. ${ }^{18}$ One interpretation of this finding is that a firm with greater international experience is able to bear the risk of an acquisition and to integrate subsidiaries of diverse managerial nationality. Along these lines, the greater the multinationality, the greater a firm's ability to acquire; the lesser the multinationality, the more likely a firm will share the risks and management responsibility through a joint venture. Multinationality should, thus, favor the ability to acquire.

Asset Size [U.S. Asset Size and Non-U.S. Asset Size].

It stands to reason that the larger the investing firm, the greater its ability to acquire. Despite the logic, the empirical evidence is mixed. Dubin [1975] found that smaller firms tended to acquire relatively more frequently than large firms, though he did not control for other factors. In his cross-sectional tests, Wilson [1980] confirmed Dubin's findings. However, these studies drew upon entry data of the largest corporations of the United States and other European countries. Caves and Mehra [1986] study did not restrict their attention to entries of the larger corporations. Their results showed that the size of the entering firm is positively and significantly related to entry by acquisition over greenfield. Because acquisitions require generally more financial and managerial resources than joint ventures, size of the foreign firm's assets should be positively correlated with the tendency to acquire. Conversely, acquisitions are discouraged, the larger the assets of the American partner, target firm, or investment size.

\section{Industry-level Variables}

\section{Industry Variables [R\&D and Advertising].}

One explanation for the country pattern is that countries differ in their industrial structures and that choice of entry modes will be influenced by the characteristics of the industry. Because of a substantial literature confirming their importance, 
industry $R \& D$ expenditures to sales and industry media and advertising expenditures to sales were chosen as control variables in the statistical investigations. ${ }^{19}$ Data on both variables are taken from the Federal Trade Commission's Line of Business study for 1975. ${ }^{20}$

Conventionally, the relationship of these variables to entry choice is said to discourage joint ventures in order to preserve proprietary assets and to discourage unrelated acquisitions. The previous empirical studies have assumed, however, foreign entry was usually for the purpose of market access or low cost manufacturing. Clearly, foreign entry into the United States may be motivated in order to source technology or purchase brand labels.

The more diverse motives of investing in the American economy make it more difficult to sign the structural variables. For example, firms from R\&D-intensive industries might joint venture if they possess the requisite technologies but lack the marketing depth. Or they may tend to acquire if they are investing for technology sourcing. Similarly, firms from marketing-intensive industries might engage in a joint venture if they possess the brand label but lack other resources along the value-added chain. Or they may acquire if they are investing for market penetration and lack label recognition. Stopford and Wells [1972] found that American firms pursuing an advertising-intensive strategy tend to full ownership of their overseas subsidiaries. Their data is drawn, however, from a time when American firms were investing overseas with clear strategic advantages. For our study, it is equally likely that foreign firms are investing in the United States for technology and brand label acquisition as for the exploitation of their proprietary assets. No prediction is made, therefore, on the signs of the coefficients for $R \& D$ and Advertising. ${ }^{21}$

\section{Sectoral Dummies [Manufacturing and Services].}

Two sectoral dummies are used in order to control for other exogenous effects not captured by the $R \& D$ and Marketing variables. These dummies are required because there are clear patterns in the modes of entry across services, extractive, and manufacturing industries and we wish to control for sectoral effects not captured by the structural variables. (See Table 1.) Because Japanese firms are active in joint ventures and manufacturing, there would be a bias towards overstating the Japanese contribution in the total number of manufacturing entries and in joint ventures. To avoid a bias, sectoral effects are controlled by using dummies for whether the entry is in manufacturing or in services.

\section{Country-level Variables}

As noted earlier, previous studies have pinpointed uncertainty as a significant influence upon the investment decision. Whereas uncertainty has been multiply interpreted, one interpretation concerns the ability of the foreign firm to manage the local operations of its subsidiary. The perceived ability to manage may be influenced by two considerations, one concerns the absolute cultural attitudes towards uncertainty avoidance, the second concerning the relative cultural distance between the country of the investing firm and the country of entry. 
Both considerations are proxied in the specification of the regression equations through the use of variables entitled uncertainty avoidance and cultural distance.

The measures for uncertainty avoidance and cultural distance are derived from the work of Hofstede [1980]. Hofstede found that differences in national cultures vary substantially along four dimensions. These dimensions were labeled uncertainty avoidance, individuality, tolerance of power distance, and masculinity-femininity. Hofstede created ordinal scales for countries for each of these dimensions based on a standardized factor analysis of questionnaires administered between 1968 and 1972 to 88,000 national employees in more than 40 overseas subsidiaries of a major American corporation. Bias for differences in occupational positions among subsidiaries was controlled. As the study consisted of two questionnaires separated by a four-year interval, it was possible to test for the reliability in scores over time; only questions showing a greater than .5 correlation in scores were used to derive the scales.

The indices of Hofstede can be criticized for a number of reasons, especially regarding the internal validity of the dimensions and the method of constructing the scales. ${ }^{22}$ Whereas the criticism has a sound basis, Hofstede's study has some appealing attributes, namely, the size of the sample, the codification of cultural traits along a numerical index, and its emphasis on attitudes in the workplace. Our use of the indices are, furthermore, conservative, for if they are poor constructs, they are less likely to be found significant and with the a priori predicted sign.

Based on these scales, the statistical analysis used two cultural variables to test the two hypotheses.

\section{Cultural Distance [Cultural Distance].}

We hypothesize that the more culturally distant the country of the investing firm from the United States, the more likely the choice to set up a joint venture. Using Hofstede's indices, a composite index was formed based on the deviation along each of the four cultural dimensions (i.e., power distance, uncertainty avoidance, masculinity/femininity, and individualism) of each country from the United States ranking. The deviations were corrected for differences in the variances of each dimension and then arithmetically averaged. Algebraically, we built the following index:

$$
C D_{j}=\sum_{i=1}^{4}\left\{\left(I_{i j}-I_{i u}\right)^{2} / V_{i}\right\} / 4,
$$

where $I_{i j}$ stands for the index for the $i$ th cultural dimension and $j$ th country, $V_{i}$ is the variance of the index of the $i$ th dimension, $u$ indicates the United States, and $C D_{j}$ is cultural difference of the $j$ th country from the United States. Though the scaling method imposes weights based on index variance, any resultant measurement error cannot be expected to be correlated theoretically with the other independent variables and should reduce the significance of the statistical relationships. 
TABLE 3

\section{Summary of Predicted Signs}

\begin{tabular}{lcc}
\hline Variable & Joint Venture & Greenfield \\
\hline Diversified & - & - \\
Experience & - & - \\
Multinational & - & - \\
U.S. Asset Size & + & + \\
Non-U.S. Asset Size & - & - \\
R \&D & $\mathrm{NP}$ & $\mathrm{NP}$ \\
Advertising & $\mathrm{NP}$ & $\mathrm{NP}$ \\
Manufacturing & $\mathrm{NP}$ & $\mathrm{NP}$ \\
Services & $\mathrm{NP}$ & + \\
Cultural Distance & + & + \\
Uncertainty Avoidance & + & + \\
\hline
\end{tabular}

*NP - No Prediction

\section{Uncertainty Avoidance [Uncertainty Avoidance].}

Uncertainty avoidance should not be understood as referring to the individual's willingness to bear risk or as the risk profile of a firm regarding its product strategy. Rather, the elements making up the dimension are organizational and managerial in character. The construction is fortunate for our purposes, as we wish to isolate the influence of cultural attitudes towards uncertainty over organizational functions, such as employment relations. The more uncertainty avoiding a culture tends to be, the less attractive is the acquisition mode due to the organizational risks of integrating foreign management into the parent organization.

The above discussion is summarized in Table 3.

\section{MODEL SPECIFICATION}

The decision to enter by acquisition, joint venture, or greenfield is modeled as a qualitative choice problem. A multinomial logit model is specified to estimate the effect of the explanatory factors on the probability that each of the three alternatives would be chosen. The multinomial logit allows the explanatory variables to affect differential odds of choosing one alternative relative to another. Thus, the coefficient vector is specific to the alternative, not to the firm making the choice [Judge et al. 1985, pp. 770-72]. Consequently, the specification of the probabilities is:

$$
P_{i j}=\exp \left(x_{i j} B_{j}\right) / \sum_{j=1}^{j=3} \exp \left(x_{i j} B_{j}\right)
$$

where $P_{i j}$ is the probability that the ith firm will choose alternative $j, x_{i j}$ is a vector of variables representing the variables characterizing the $i$ th firm and the $j$ th governance mode and $B_{j}$ is the vector of coefficients to the independent variables. However, since the probabilities are constrained to sum to one, the system of equations are over-identified. The parameters can be estimated by setting the $B$ s of one of the alternatives to 0 . In our model, it stands to reason 
to use acquisitions as the baseline case by which to compare the estimated parameters of the other alternatives (joint venture or greenfield).

Under this condition, the specification is reduced to:

$$
P_{i j}=\exp \left(x_{i j} B_{j}\right) / 1+\sum_{e=2}^{3} \exp \left(x_{i j} B_{i}\right)
$$

with the baseline alternative specified as

$$
P_{i 1}=1 / 1+\sum_{e=2}^{3} \exp \left(x_{i j} B_{j}\right) .
$$

The parameters $(B \mathrm{~s})$ are estimated by maximizing a log likelihood function using the Newton-Raphson iteration procedure. ${ }^{23}$

Unfortunately, values for $R \& D$ and Advertising are only available for manufacturing. Since missing values eliminate the entire case from the sample, we follow a technique suggested by Johnston (1972, pp. 238-41). ${ }^{24}$ We treat the manufacturing, service, and extractive as three equations with explanatory variables which are not identical. For the nonmanufacturing sectors, $R \& D$ and Advertising are recorded as 0 . If we assume the disturbance terms are not correlated, we can run a single multinomial estimation. The dummy variables will pick up the sectoral differences.

\section{RESULTS}

The results are provided in Table 4. The estimated coefficients should be interpreted as representing the marginal utility of choosing a joint venture or wholly owned greenfield relative to an acquisition. A positive coefficient signifies that the greater the value of the independent variable, the more likely the alternative (i.e., joint venture or acquisition, as the case may be) will be chosen; the converse is true for a negative sign. $T$-test statistics are given in parentheses.

The estimated parameters for the equation using cultural distance show strong support for the first hypothesis. The effect of Cultural Distance is to increase the probability of choosing a joint venture over an acquisition and is significant at the .001 level. Its effect is, however, only significant at the .1 level for greenfield. (We are using a conservative two-tail test, though arguably we could apply, following Caves and Mehra, a one-tail test to the coefficients for which we have predicted signs.) The results for Uncertainty Avoidance are more impressive, with the coefficients correctly signed and significant at .001 and .05 for joint venture and greenfield, respectively.

The asset size variables generally are correctly signed. The effect of U.S. Asset Size on choosing a joint venture is significant at .001. Clearly, the larger the size of the American partner, the more likely to joint venture than acquire. The effect of U.S. Asset Size on choosing greenfield is negative and significant in both the uncertainty avoidance and cultural distance runs at the .1 and .05 level, respectively. It is likely, however, that this result stems from the 


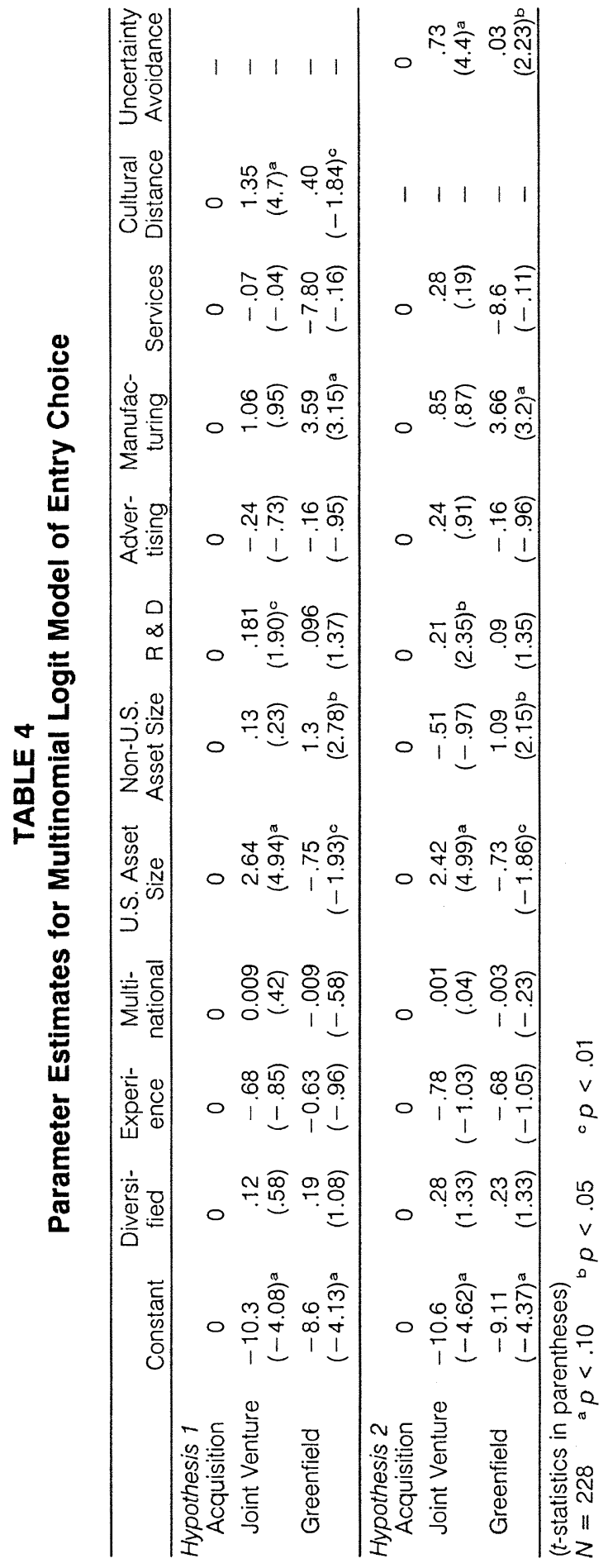


measurement of asset size for greenfield in terms of the investment and for acquisition or joint venture in terms of the asset size of the target or partner. The effect of the Non-U.S. Asset Size is insignificant for the case of joint venture in the cultural distance estimation, but correctly signed, though still insignificant, for the uncertainty avoidance estimation. Interestingly, larger size of the foreign firm encourages greenfield over acquisition at the .01 level in the cultural distance run and .05 in the uncertainty avoidance run; this result confirms the finding of Dubin.

Experience and Multinationality are correctly signed (with the exception of the coefficient to Multinationality for joint venture in the Uncertainty Avoidance estimation.). However, the $t$-tests are not significant. Similar to earlier studies, therefore, experience effects as measured by prior entries are not shown to be robust under large-sample multiple regression estimates. Unlike some other studies (e.g., Caves and Mehra [1986], and Gatignon and Anderson [1987]), our measure for multinational experience is not found to be significant.

We also do not find diversified firms more likely to enter by acquisition. To the contrary, the variable Diversified is positively signed, showing that diversified firms tend to enter by joint venture or greenfield. The results are not significant and it would be premature at this time to speculate on the causes.

The industry sectoral variables are of some interest. Of the dummy variables, only Manufacturing is significant in both equations, indicating a preference for greenfield investment over acquisition in the manufacturing sector. As shown later, this effect is almost entirely due to Japanese investments.

The most interesting of the industry-level variables is the positive effect of $R \& D$ on joint venture and greenfield entry, though only significant in the former case (at .1 for the cultural distance estimation and .05 for uncertainty avoidance). Elsewhere, we have shown that joint ventures appear to be particularly encouraged in growing and R\&D-intensive industries [Kogut and Singh 1987]. This result is counter to previous findings and some transaction cost arguments. A possible interpretation is that non-U.S. firms enter the United States to tap into American technology by joint ventures. At a minimum, given the positive sign to $R \& D$ for both joint ventures and greenfield (though not significant for the latter), acquisitions appear to be discouraged in high $\mathrm{R} \& \mathrm{D}$-intensive industries.

Advertising is negatively related to joint ventures and greenfield investments. Though the results are not significant, they are consistent with Caves and Mehra's [1986] argument that acquisitions are favored for the purpose of brand label or product adaptation. This relationship is expected to be more pronounced for mature industries, which we will explore more fully in further work.

\section{CONTROLLINGG FOR JAPANESE ENTRIES}

It could be argued that the cultural results are driven by outliers, namely, that Japan scores highly distant in culture from the United States and scores high on uncertainty avoidance. At the same time, Japanese firms tend toward 
greenfield and joint venture entries. Thus, the results could be interpreted as a primarily Japanese effect.

From one point of view, Japan as an outlier is consistent with our argument and this result should be expected to hold for entries from other countries that are culturally different from the United States but whose firms have yet to establish a strong foreign investment position. Nevertheless, the effects of cultural distance and uncertainty avoidance should be expected to hold for the sample in the absence of Japanese entries. To show this, we reestimate the earlier equations on a subsample of the data, having removed the Japanese cases. These results are given in Table 5.

The effects of culture are indeed weaker but still correctly signed and significant in two cases. Cultural Distance is significant at .05 for joint ventures and just shy of .15 for greenfield. (Again, it is important to note that under a one-tail test, it is significant at .1.) The Uncertainty Avoidance effect is negligible in the case of joint ventures but significant at .05 for greenfield.

The other effects remain largely the same as before, except for changes in significance. Interestingly, Multinationality is positively signed, showing that acquisitions are discouraged for the more multinational of corporations. On the other hand, Experience increases in significance in the runs, and is significant in three of the runs at .1 using a one-tail test. The positive effect of $R \& D$ for joint ventures remains significant at the .05 level in both runs. The manufacturing dummy coefficient is highly insignificant. Clearly, then, the earlier sectoral effect is driven by the sectoral preference of Japanese firms.

In summary, the statistical estimations provide strong support that cultural distance and national attitudes towards uncertainty avoidance influence the choice of entry mode. It should be underlined that these relationships are robust despite the controls added for industry- and firm-level effects. The weaker results for the subsample when the Japanese entries are removed are partly a result of the reduced sample size (the cases drop from 228 to 173) and partly a result of the outlier effect of Japan. ${ }^{25}$ It is impressive, therefore, that cultural effects appear to be still persistent despite the reduction in sample size and the diminishment in variance of the cultural variables.

\section{CONCLUSIONS}

The above results offer the first large-sample multiple regression test of the prevailing view that entry mode selection is influenced by cultural factors. The results have a secondary implication in terms of validating the usefulness of Hofstede's measures of cultural dimensions. Unquestionably, a scale measuring the cultural characteristics at the firm level would be preferable. Yet, the collection of such data appears formidable at this time. It is, therefore, all the more remarkable that the strength of the results were found, despite using measures of national cultural attitudes which were developed for other purposes.

The results should be interpreted with care. The variable of uncertainty avoidance is defined in the context of organizational and managerial preferences; it is not a measure of cultural attitudes towards risk in a larger sense. Furthermore, 


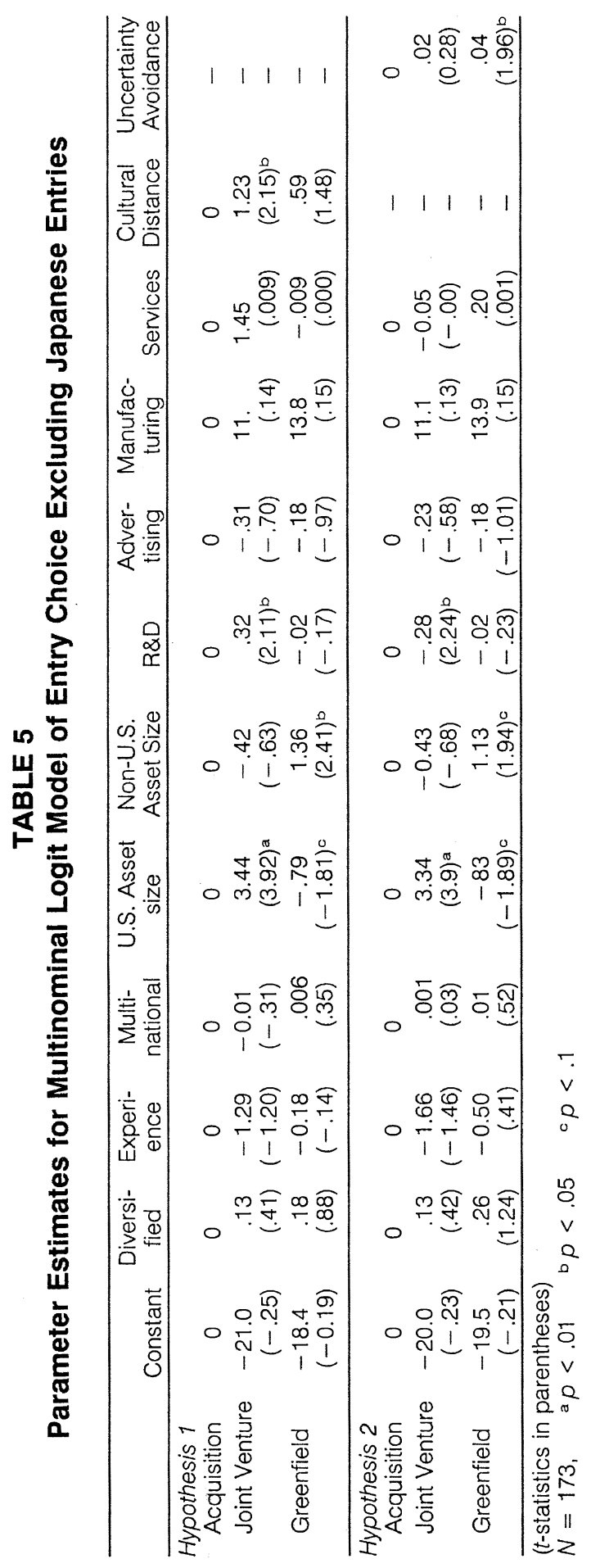


the results may only have validity within a particular historical time. Since foreign direct investment has been concentrated historically between the United States and Europe, which are relatively culturally similar, there are confounding effects of cultural distance and experience. As Japan and other Asian countries continue to increase their overseas investments in the West, cultural distance may be increasingly offset by growing experience at the firm level. Though we have tried to control for such effects, it could well be that our proxy variables were insufficient.

A final consideration which deserves further exploration is a more refined analysis of entry decisions in the context of oligpolistic gaming. Competitive dynamics, such as the rush to invest, are likely to influence the entry choice. In addition, the relationship among the variables may change depending on the functional purpose of the entry. Both refinements are the subject of current work.

The results have a wider implication outside of country patterns and the choice of entry. The above study suggests that when economic choice is compared across countries, cultural characteristics are likely to have profound implications. Whereas theories of internalization and the firm may be culturally robust, their empirical application in a comparative setting appears to warrant the consideration of cultural differences on the costs and risks which managers attach to different modes of transacting.

Whether these results are interpreted as contradicting an internalization theory of entry choice is largely a question of the definition of transaction costs. To some, transaction costs are broadly defined to include communication and control costs, even if these costs are derived from cultural factors. In our view, it is theoretically and empirically interesting to distinguish between transaction costs that are independent of a firm's country of origin and those that are determined by cultural factors. The multinational corporation is the heir, to use Philip Curtin's [1984] expression, of the historical cross-cultural broker in world trade. But no matter how superior the current multinational corporation may be in replacing the skills of traders by the international extension of organizational boundaries, the management of these firms are likely to be influenced by the dominant country culture. The results of this paper suggest that further investigation into the cultural determinants of managerial decisionmaking is soundly warranted.

\section{APPENDIX DATA SOURCES}

Data on joint ventures, acquisitions, and greenfield are not compiled systematically by the United States government and must, therefore, be gleaned from a number of publicly-available sources. Data on acquisitions were taken from two sources: the Department of Commerce's publication Foreign Direct Investment in the United States for the years 1981 to 1985 and Mergerstat Review, W.T. Grimm \& Company, Chicago, 1984, for the years 1981, 1982 and 1983. Acquisitions valued less than $\$ 10$ million were excluded. In addition 
to the Commerce publication cited above, sources used for joint ventures were: Mergers and Acquisitions and the Yearbook on Corporate Mergers, Joint Ventures, and Corporate Policy. For the statistical investigation, data for joint ventures were taken for the years 1981 to 1985 . Data on greenfield investments were found in Foreign Direct Investment in the United States, again for the years 1981 to 1985 .

\section{NOTES}

${ }^{1}$ For a review, see Ajami and Ricks [1981]; Arpan, Flowers and Ricks [1981]; McClain [1983]; and Hood and Young [1980].

${ }^{2}$ An exploratory investigation of strategic motives for the choice of entry is provided in Kogut and Singh [1987].

${ }^{3}$ For an extensive argument along these lines, see Robbins [1987].

${ }^{4} \mathrm{~A}$ joint venture is both legally and conceptually different from a minority equity participation investment, where a firm invests directly into a second company but does not share control with a third party.

${ }^{5}$ We would like to thank Jean-Francois Hennart for this observation on the Anderson-Gatignon paper, which came to our attention subsequent to submitting this article for review.

${ }^{6}$ Caves (1982, chap. 3) argues similarly in his discussion on the joint determination of exporting and foreign direct investment.

${ }^{7}$ The main findings are reported in Hornell, Vahlne and Wiedersheim-Paul [1973]. A brief English description is given in Johanson and Vahlne [1977].

${ }^{8}$ The numerous anecdotes on the motivations of Japanese firms to invest in greenfield sites in rural areas are consistent with this argument.

${ }^{9}$ It is important to note that our hypothesis is stated at the country level to represent average tendencies. We cannot make statements to the particular firm without more detailed knowledge of the correspondence of the national to corporate culture.

${ }^{10}$ Cultural distance is, in most respects, similar to the "psychic distance" used by the Uppsala school.

${ }^{11} \mathrm{~A}$ common confusion is to treat uncertainty avoidance as equivalent to risk attitudes in general. We, in agreement with Hofstede [1980], use uncertainty avoidance in the original sense of Cyert and March to refer to the way uncertainty is organizationally resolved as separate from the issue of whether an organization or firm chooses or avoids risky environments for a given return.

${ }^{12}$ Wilson's data also came from the Multinational Data Base on 187 U.S. multinationals for the period up to 1967, plus from the activities of 202 foreign-based multinationals through 1971 .

${ }^{13}$ They called this variable an experience effect, but in order to be consistent with our description of similar variables in other studies, we have relabeled it as a measure of multinationality in accordance with Caves and Mehra.

${ }^{14}$ Another interpretation is that the results confirm that firms maintain in-house what Dunning [1977] calls "ownership advantages".

${ }^{15}$ R. David Belli, "U.S. Business Enterprises Acquired or Established by Foreign Direct Investors in 1983," Survey of Current Business, Department of Commerce, 1984.

${ }^{16}$ Though high, it is lower than the $73 \%$ reported by Tsurumi [1976] for Japanese overseas manufacturing subsidiaries in 1971. However, Tsurumi included subsidiaries in which Japanese firms had less than $25 \%$ share. If we take out these subsidiaries (which are better considered as minority investments), then the percentage is $60 \%$. Caves reports Tsurumi's estimate as $82 \%$, but we have been unable to locate the source of the figure [Caves 1982, pp. 89-90].

${ }^{17}$ Caves and Mehra [1985] proxied experience by whether the firm had made a previous investment in the United States. Wilson [1980] used the proportion of subsidiaries established before an arbitrarily chosen breakpoint.

${ }^{18}$ On the other hand, Steuber et al. [1973] found that the percentage of equity share in a United Kingdom subsidiary by a foreign firm increased with the multinationality of the parent. 
${ }^{19}$ For a summary of studies on R\&D and advertising, see Scherer [1980, chaps. 14 and 15]. For a summary of research on the relation of R\&D and advertising to foreign entry choice, see Caves [1982, chap. 1].

${ }^{20}$ The line of business data are drawn from confidential government surveys of businesses. Though somewhat dated, the published summary statistics for R\&D have been found to be reasonably stable over time. For evidence, see Scherer [1982]. We have made a parallel assumption for Advertising expenditures.

${ }^{21}$ This argument is consistent with Caves and Mehra [1986].

${ }^{22}$ Hofstede [1980] points out, however, that the external validity is reasonable high when tested against other variables which should be correlated with cultural differences.

${ }^{23}$ We would like to thank Hubert Gatignon for sharing his program and his advice with us.

${ }^{24} \mathrm{We}$ are indebted to Tom Pugel for this suggestion.

${ }^{25}$ Attempts to avoid the loss in sample size by using a country dummy for Japan with the full sample floundered due to the collinearity between the Japan dummy and cultural measures (.81 for Cultural Distance and .86 for Uncertainty Avoidance).

\section{REFERENCES}

Abbegglen, J.C. \& G. Stalk. 1984. The role of foreign companies in Japanese acquisitions. The Journal of Business Strategy, 4:3-10.

Ajami, R.A. \& D.A. Ricks. 1981. Motives of non-American firms investing in the U.S. Journal of International Business Studies, 13 (Winter):25-34.

Arpan, J.S., E.B. Flowers \& D.A. Ricks. 1981. Foreign direct investment in the United States. Journal of International Business Studies, 12 (Spring/Summer):137-54.

Bendix, Reinhard. 1956. Work and authority in industry: Ideologies of management in the course of industrialization. Berkeley:University of California.

Brooke, M.Z. \& H.L. Remmers, eds. 1972. The multinational company in Europe: Some key problems. London: Longman.

Caves, Richard. E. 1982. Multinational enterprise and economic analysis. Cambridge, U.K.: Cambridge University Press.

\& S. Mehra. 1986. Entry of foreign multinationals into U.S. manufacturing industries. In M. Porter, ed., Competition in global industries. Boston: Harvard Business School.

Curtin, Philip. 1984. Cross-cultural trade in world history. London: Cambridge University Press.

Davidson, William H. 1980. The location of foreign direct investment activity: Country characteristics and experience effects. Journal of International Business Studies, 12 (Fall):9-22.

Dubin, Michael. 1975. Foreign acquisitions and the spread of the multinational firm. D.B.A. thesis, Graduate School of Business Administration, Harvard University.

Dunning, John. 1977. Trade, location of economic activity and the MNE: A search for an eclectic theory. In B. Ohlin, ed., The international allocation of economic activity. London: Holmes and Meier.

Franko, Lawrence G. 1976. The European multinationals. Stanford, CT: Greylock Publishers.

Gatignon, H. \& E. Anderson. 1987. The multinational corporation's degree of control over foreign subsidiaries: An empirical test of a transaction cost explanation. Report Number 87-103, Marketing Science Institute, Cambridge, Massachusetts.

Hofstede, Geert. 1980. Culture's consequences: International differences in work-related values. Beverly Hills: Sage Publications.

Hood, N. \& S. Young. 1980. Recent patterns of foreign direct investment by British multinational enterprises in the United States. National Westminster Bank Quarterly Review: 21-32.

Hornell, E., J.E. Vahlne \& F. Wiedersheim-Paul. 1973. Export och utlandsetableringar. Uppsala: Almqvist \& Wiksell.

Hymer, Stephen. 1960. The international operations of national firms: A study of direct foreign investment. Ph.D. thesis, Department of Economics, Massachusetts Institute of Technology.

Jemison, D.B. \& S.B. Sitkin. 1986. Corporate acquisitions: A process perspective. Academy of Management Review, 11:145-63. 
Johanson, J. \& J.E. Vahlne. 1977. The internationalization process of the firm-A model of knowledge development and increasing foreign market commitments. Journal of International Business Studies, 8 (Spring/Summer):22-32.

Johnston, J. 1972. Econometric methods. New York: McGraw-Hill.

Judge, G., W. Griffiths, R. Hill, H. Luetkephl \& T. Lee. 1985. The theory and practice of econometrics. New York: John Wiley.

Kogut, B. 1987. Joint ventures: Theoretical and empirical perspectives. Strategic Management Journal, forthcoming.

\& H. Singh. 1987. Entering the United States by joint venture: Industry structure and competitive rivalry. In F. Contractor \& P. Lorange, eds., Cooperative Strategies in International Business. Lexington, MA: Lexington Press.

Lincoln, J.R., M. Hanada \& J. Olson. 1981. Cultural orientations and individual reactions to organizations: A study of employees of Japanese-owned firms. Administrative Science Quarterly, 25:93-115.

McClain, David. 1983. Foreign direct investment in the United States: Old currents, "new waves," and the theory of direct investment. In C.P. Kindleberger \& D. Audretsch, eds., The Multinational Corporation in the 1980s. Cambridge, MA: MIT Press.

Pate, James L. 1969. Joint venture activity, 1960-1968. Economic Review, Cleveland: Federal Reserve Board.

Pugel, T.A. 1981. Technology, transfer and the neoclassical theory of international trade. In R.G. Hawkins \& A.J. Prasad, eds., Technology Transfer and Economic Development. Greenwich, CT: JAI Press.

Puxty, A.G. 1979. Some evidence concerning cultural differentials in ownership policies of overseas subsidiaries. Management International Review, 19:39-50.

Robbins, James. 1987. Organizational economics: Notes on the use of transaction cost theory in the study of organizations. Administrative Science Quarterly, 32:68-86.

Robinson, Richard D. 1961. Management attitudes toward joint and mixed ventures abroad. Western Business Review.

Sales, A.L. \& P.H. Mirvis. 1984. When cultures collide: Issues in acquisition. In Managing organizational transitions. Homewood, IL: Irwin.

Scherer, F.M. 1980. Industrial market structure and economic performance. Chicago: Rand McNally College Publishing Company.

1982. Inter-industry technology flows and productivity growth. Review of Economics and Statistics, 64 (November): 627-34.

Steuber, M.D. et al. 1973. The impact of foreign direct investment on the United Kingdom. London: Department of Trade and Industry.

Stopford, J. \& L. Wells. 1972. Managing the multinational enterprise: Organization of the firm and ownership of the subsidiaries. New York: Basic Books.

Stopford, J.M. \& K.O. Haberich. 1978. Ownership and control of foreign operations. In M. Ghertman \& J. Leontiades, eds., European Research in International Business, pp. 141-67. Amsterdam: North Holland.

Wilson, Brent. 1980. The propensity of multinational companies to expand through acquisitions. Journal of International Business Studies, 12 (Spring/Summer):59-65. 